\title{
Age- and Level-Dependence of Fatty Infiltration in Lumbar Paravertebral Muscles of Healthy Volunteers
}

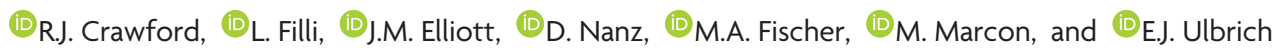

\begin{abstract}
BACKGROUND AND PURPOSE: Normative age-related decline in paravertebral muscle quality is important for reference to disease and risk identification in patients. We aimed to establish age- and vertebral level-dependence of paravertebral (multifidus and erector spinae) muscle volume and fat content in healthy adult volunteers.
\end{abstract}

MATERIALS AND METHODS: In this prospective study multifidus and erector spinae fat signal fraction and volume at lumbar levels L1-L5 were measured in 80 healthy volunteers ( 10 women and men per decade, $20-62$ years of age) by 2-point Dixon 3T MR imaging. ANOVA with post hoc Bonferroni correction compared fat signal fraction and volume among subgroups. Pearson and Spearman analysis were used for correlations $(P<.05)$.

RESULTS: Fat signal fraction was higher in women $(17.8 \% \pm 10.7 \%)$ than men $(14.7 \% \pm 7.8 \% ; P<.001)$ and increased with age. Multifidus and erector spinae volume was lower in women $\left(565.4 \pm 83.8 \mathrm{~cm}^{3}\right)$ than in men $\left(811.6 \pm 98.9 \mathrm{~cm}^{3} ; P<.001\right)$ and was age-independent. No differences in fat signal fraction were shown between the right and left paravertebral muscles or among the L1, L2, and L3 lumbar levels. The fat signal fraction was highest at L5 (women, 31.9\% $\pm 9.3 \%$; men, $25.7 \% \pm 8.0 \% ; P<.001$ ). The fat signal fraction at L4 correlated best with total lumbar fat signal fraction (women, $r=0.95$; men, $r=0.92, P<.001$ ). Total fat signal fraction was higher in the multifidus compared with erector spinae muscles at L1-L4 for both sexes $(P<.001)$.

CONCLUSIONS: Lumbar paravertebral muscle fat content increases with aging, independent of volume, in healthy volunteers $20-62$ years of age. Women, low lumbar levels, and the multifidus muscle are most affected. Further study examining younger and older subjects and the functional impact of fatty infiltrated paravertebral muscles are warranted.

ABBREVIATIONS: $\mathrm{BIA}_{\mathrm{foot}}=$ Tanita UM-081 bio-impedance fat analyzer; $\mathrm{BIA}_{\text {hand }}=$ Omron $\mathrm{BF} 300$ bioimpedance fat analyzer; $\mathrm{BMI}=$ body mass index; $\mathrm{ES}=$ erector spinae (longissimus and iliocostalis combined); FSF = fat signal fraction; LBP = low back pain; MF = multifidus; $M F I=$ muscle fat infiltration

M $\mathrm{R}$ imaging is the criterion standard for evaluating the size and structure of soft-aqueous skeletal muscles. ${ }^{1,2}$ While T1WI is commonly used for qualitative assessment of muscle fat infiltration (MFI), ${ }^{3,4}$ chemical-shift-based imaging sequences allow quantification, ${ }^{5-7}$ which correlates with clinical symptoms ${ }^{3,8}$ and histology. ${ }^{2,9}$

The Dixon technique is a robust chemical-shift imaging application producing water- and fat-only images from dual-echo ac-

Received August 5, 2015; accepted after revision September 11.

From the Centre for Health Sciences (R.J.C., J.M.E.), Zurich University of Applied Sciences, Winterthur, Switzerland; Faculty of Health Professions (R.J.C.), Curtin University, Perth, Australia; Institute of Diagnostic and Interventional Radiology (L.F., D.N., M.A.F., M.M., E.J.U.), University Hospital and University of Zurich, Zurich, Switzerland; Feinberg School of Medicine (J.M.E.), Northwestern University, Chicago, Illinois; School of Health and Rehabilitation Sciences (J.M.E.), University of Queensland, Brisbane, Australia; and Institute of Diagnostic Radiology (M.M.), University Hospital Santa Maria della Misericordia, Udine, Italy.

This work was supported by the University Zürich Research Program "Research Time for Clinical Research at the Medical Faculty of University Zurich" (grant RT-13-014) quisitions. $^{10,11}$ Excellent accuracy for MFI quantification is shown in comparison with T1WI, ${ }^{12}$ spectroscopy, ${ }^{5}$ and histology in different animal species. ${ }^{9}$ Accordingly, Dixon MR imaging was used for evaluating muscle fat content in several clinical studies including patients with low back pain (LBP), ${ }^{5,13}$ acute-to-chronic whiplash, ${ }^{14}$ and neuromuscular disorders. ${ }^{15}$

Quantification of degeneration (fat infiltration and atrophy) of lumbar paravertebral muscles has attracted interest in understanding their biologic influence on persistent LBP. Atrophy and fat infiltrates are identified in patients ${ }^{16-21}$ and following experimentally induced lesions in a porcine model. ${ }^{22}$ However, human studies describing lumbar MFI report inconsistent findings: An

Please address correspondence to Rebecca Crawford, PhD, Health Professions, ZHAW, Zurich University of Applied Sciences, Technikumstr 71, CH-8401, Winterthur, Switzerland; e-mail: rebecca.crawford@zhaw.ch

\footnotetext{
三 Indicates article with supplemental on-line tables.

Indicates article with supplemental on-line photo

http://dx.doi.org/10.3174/ajnr.A4596
} 
association with LBP was demonstrated in some $e^{18,23-26}$ but not in others. $^{13,16}$

One explanation for discrepant findings is the influence of age on muscle composition. ${ }^{17,18,27-29}$ Spinal degeneration is known to occur early and increasingly throughout the life span, ${ }^{30}$ yet to our knowledge, no study has assessed age-related morphologic changes to lumbar paravertebral muscles in healthy volunteers, which would provide a crucial supplement for future comparative studies.

We sought to quantify lumbar paravertebral muscle volume and fat content by 2-point Dixon MR imaging in healthy adult volunteers spanning 4 decades of life, and we aimed to establish an age- and level-dependent reference of lumbar paravertebral muscle volume and fat content as a reflection of natural aging history. We hypothesize greater MFI with age for both sexes and lumbar MFI level-dependence with an increasing craniocaudal trend.

\section{MATERIALS AND METHODS}

This study was approved by the University Hospital Zurich institutional review board, participants provided written informed consent, and no authors had financial interests.

\section{Study Participants}

Eighty subjects from a larger $(n=104)$ prospective clinical trial investigating whole-body MRI of healthy adult volunteers (between October 2011 and April 2014) were examined. Forty women $(39.0 \pm 11.6$ years of age; range, $21-62$ years $)$ and 40 men $(40.0 \pm 11.2$ years of age; range, $20-61$ years $)$ with 10 cases for each sex were represented across 4 decades: 20-29, $30-39,40-49$, and $50-62$ years ( 1 subject per sex older than 60 years of age).

Participants were recruited via advertisements on the intranet and clinical trials Web site of the University Hospital $\mathrm{Zu}$ rich. Volunteers were screened by using the "Swiss Olympics' First Sports Medicine Interview" health survey, including comprehensive questions determining medical history, handand leg-dominance, weight change (yes/no), smoker (yes/no), alcohol and drug use, and exercise (moderate/high or low). Musculoskeletal pain or injury was determined by the following question: "Do you currently or have you had injuries/ symptoms/operations of the musculoskeletal system?" In response to this question, 16 body parts (including low back), plus an option of "other," were marked yes or no; only responders answering no for all 16 body parts were included.

Subjects progressed to clinical examination when the selfreported height- and weight-registered body mass index (BMI) was between 18 and $26 \mathrm{~kg} / \mathrm{m}^{2}$ by using the following formula: Weight $/$ Height ${ }^{2}\left(\mathrm{~kg} / \mathrm{m}^{2}\right){ }^{31}$ Exclusion criteria were the following: contraindications for MR imaging (claustrophobia, metal, pacemaker, pregnancy); previous arthrodesis surgery; systemic diseases (chronic obstructive pulmonary diseases, diabetes, metabolic diseases, rheumatologic disorders, tumors, chronic pain syndrome); vascular problems (coronary heart disease, peripheral vascular disease); and alcohol or drug abuse.

\section{Clinical Examination Pre-MR Imaging}

Barefoot standing height was measured with a wall-mounted stadiometer (nearest $0.1 \mathrm{~cm}$ ); bodyweight (kilograms) was collected via a standard scale; and BMI was derived from these 2 parameters. Two bioelectric impedance instruments were used to reflect body fat: Tanita UM-081 (foot sensor pads on a standing scale; Tanita, Arlington Heights, Illinois) $\left(\right.$ BIA $\left._{\text {foot }}\right)$, and Omron BF300 (hand sensor pads with a hand-held device; Omron Healthcare, Kyoto, Japan) $\left(\mathrm{BIA}_{\text {hand }}\right)$. Leg dominance was confirmed with a balance recovery test. ${ }^{32}$

\section{Imaging Acquisition}

Whole-body scans were performed in a 3T MR imaging scanner (Ingenia; Philips Healthcare, Best, the Netherlands). A table-integrated 15-element dS head coil, automatically centering on imaged anatomy; a 16-channel posterior coil; and two 16-channel anterior coils were used for signal reception; the dual-transmit body coil of the scanner was used for radiofrequency transmission. Subjects were supine (arms alongside the body).

MR imaging protocol included axial 2-point Dixon sequences (3D fast-field echo T1; 2 echoes; acquired voxel dimensions, 2.0, 2.0, $4.0 \mathrm{~mm}$; reconstructed voxel dimensions, 1.0, 1.0, $2.0 \mathrm{~mm}$; intersection gap, $0.0 \mathrm{~mm}$; FOV, $560 \times 352$; number of sections, 80 ; TR, $4.2 \mathrm{~ms}$; TE, 1.2 and $3.1 \mathrm{~ms}$; flip angle, $5^{\circ}$; number of signal averages, 2 ; sensitivity encoding acceleration factor, 2.0 and 2.0; foldover direction, anteroposterior; water-fat shift, 0.292 pixels; receiver bandwidth, 1485.1 $\mathrm{Hz} /$ pixel $^{-1}$; single series acquisition time, $16.4 \mathrm{~ms}$; scanning duration, 28:20 minutes). Two or 3 sequence blocks (participant height-dependent), with an acquisition time of 32.8 or $49.2 \mathrm{~ms}$, respectively, represented the lumbosacral spine.

\section{Image Analysis}

Image analysis was performed with dedicated software providing semiautomatic segmentation with linear interpolation (Myrian; Intrasense, Paris, France). An experienced musculoskeletaltrained reader (R.J.C.), skilled in MR imaging postprocessing and volumetric analyses, segmented muscles at all vertebrae between the superior endplate of $\mathrm{L} 1$ to the superior endplate of the sacrum. Each lumbar level was defined from the superior endplate of the upper vertebra to the superior endplate of the vertebra (or sacrum) immediately below, including the intervening disc. We drew left and right paravertebral muscle ROIs every third section of the axial water image, while scout-referencing equivalent fat images. The multifidus (MF), longissimus, and iliocostalis were identified as medial-to-lateral paravertebral muscles, respectively; the longissimus and iliocostalis muscles were segmented as a single region labeled "erector spinae" (ES); the border between the MF and ES was scouted from the mammillary processes. The software calculated muscle volume and mean signal intensity values of all pixels. ROIs were copied from the water images to fat images of the same sequence; mean signal intensities $\left(\operatorname{Signal}_{\text {water }}+\operatorname{Signal}_{\text {fat }}\right)$ within these ROIs were recorded (On-line Figure). Fat signal fraction (FSF) was calculated as FSF $(\%)=\left(\operatorname{Signal}_{\text {fat }} /\left[\operatorname{Signal}_{\text {water }}+\right.\right.$ Signal $\left.\left._{\text {fat }}\right]\right) \times 100 .^{33}$

AJNR Am J Neuroradiol 37:742-48 Apr 2016 www.ajnr.org 743 
Table 1: Demographics for 80 healthy adult volunteers ${ }^{a}$

\begin{tabular}{lccc}
\hline & Women $(\boldsymbol{n}=\mathbf{4 0})$ & Men $(\boldsymbol{n}=\mathbf{4 0})$ & $\boldsymbol{P}$ Value \\
\hline Age $(\mathrm{yr})$ & $39.0 \pm 11.6(21-62)$ & $40.0 \pm 11.2(20-61)$ & .22 \\
Height $(\mathrm{cm})$ & $168.0 \pm 6.2(158-183)$ & $181.7 \pm 7.3(169-200)$ & $<.001$ \\
Weight $(\mathrm{kg})$ & $61.3 \pm 7.7(43.6-86.0)$ & $76.1 \pm 7.7(56.3-92.0)$ & $<.001$ \\
$\mathrm{BMI}\left(\mathrm{kg} / \mathrm{m}^{2}\right)$ & $21.6 \pm 2.1(18.2-26.0)$ & $23.0 \pm 1.8(19.4-26.2)$ & .05 \\
$\mathrm{BIA}_{\text {foot }}(\%)$ & $27.8 \pm 5.6(12.5-38.8)$ & $17.9 \pm 4.7(5.4-31.0)$ & $<.001$ \\
$\mathrm{BIA}_{\text {hand }}(\%)$ & $21.9 \pm 5.3(13.0-33.3)$ & $14.2 \pm 4.7(5.2-22.3)$ & $<.001$ \\
Leg dominance & 28 Right, 12 left & 23 Right, 17 left & .35 \\
Hand dominance & 34 Right, 6 left & 34 Right, 6 left & 1.0 \\
\hline
\end{tabular}

Note:-BMl indicates body mass index.

${ }^{a}$ Data are mean (range)
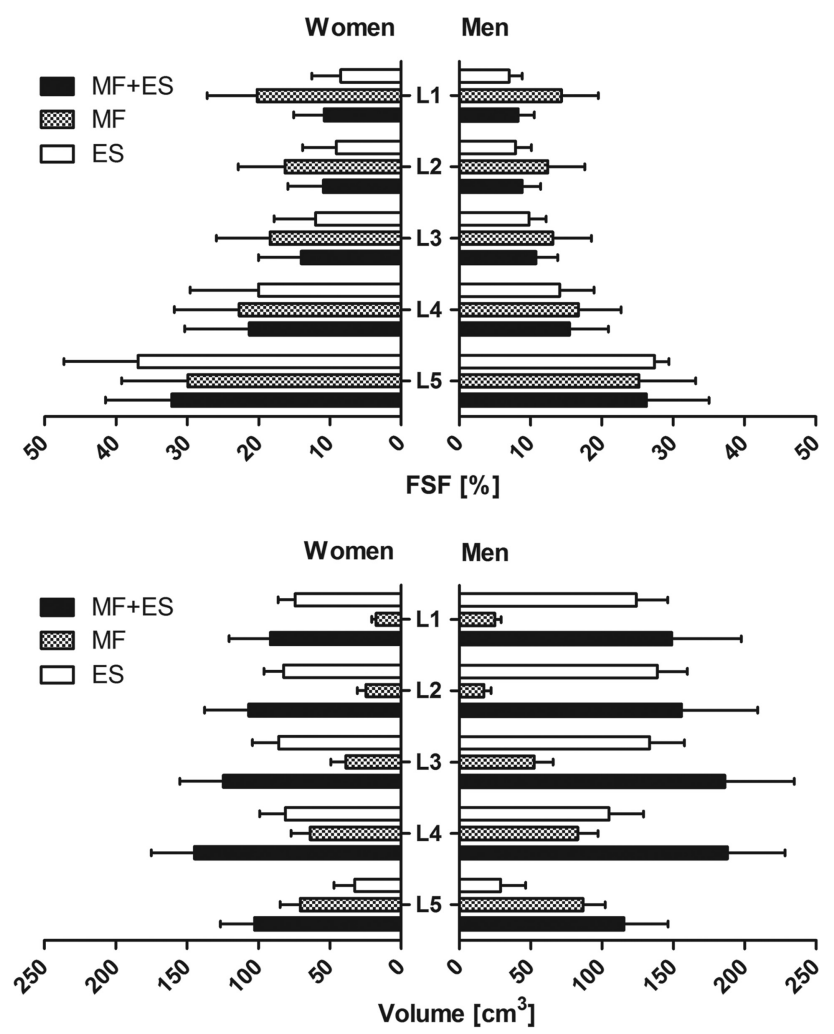

FIG 1. Fat signal fraction (percentage) and muscle volume (cubic centimeters) at each lumbar spine level (L1-L5) for women and men. Multifidus and erector spinae FSFs and muscle volumes are given separately and for FSF combined, to represent the volume-weighted average for both (MF + ES). FSF and volume are represented as the sum of both sides (left + right).

\section{Statistical Analysis}

Statistical analyses were performed by using commercial software (GraphPad Prism; GraphPad Software, San Diego, California; and SPSS, Version 20; IBM, Armonk, New York). Mean ( \pm SD) FSF and volume for MF, ES, and MF + ES were calculated for each subject. The Kolmogorov-Smirnov test verified normal distribution. The ANOVA with post hoc Bonferroni correction compared FSF and volume values among subgroups. Except for the comparison between the right and left sides as part of ANOVA, FSF and volume values of both sides were combined for statistical analysis (On-line Figure). Distributions of leg and hand dominance were compared by using the $\chi^{2}$ test. Correlations between linear parameters (FSF, age, volume, $\mathrm{BMI}, \mathrm{BIA}_{\text {foot }}$, and $\mathrm{BIA}_{\text {hand }}$ ) were assessed with the Pearson correlation coefficient $(r)$. Correlations of FSF and
BMI with categoric variables (weight change, diet, smoking, alcohol, leg/hand dominance) were evaluated by using the Spearman $r$. Correlations between 1.0 and 0.5 were considered strong; $0.5-0.3$, moderate; and 0.3-0.1, weak. Statistical significance was $P<.05$.

\section{RESULTS}

Descriptive statistics (mean $\pm \mathrm{SD}$, range) of demographics are found in Table 1. No significant differences in paravertebral muscle FSF or volume were found between the right and left sides $(P=.30)$ or hand $(P=.52)$ or leg $(P=.29)$ dominance.

FSF (percentage) and volume (cubic centimeters) (mean \pm $\mathrm{SD})$ for age group, sex, and lumbar level are presented in Online Tables 1 and 2 and are illustrated in Figs 1 and 2.

\section{Sex}

FSF for MF and ES alone and combined was higher in women than in men $(P<.001)$, whereas the volume for MF and ES alone and combined was higher in men $(P<.001)$.

\section{Age}

Volunteers 30-39 years of age (only in men, $P<.001$ ), 40-49 years (women: $P=.04$; men: $P<.001$ ), and 50-62 years (both sexes, $P<.001$ ) showed higher FSF (MF + ES) than those 20-29 years of age. In men, there was also higher FSF at 50-61 years compared with $30-39$ years $(P=.049)$ and $40-49$ years $(P=.03)$ (On-line Table 1 and Fig 2).

\section{Lumbar Level}

FSF (MF + ES) showed an increasing trend from L1 to L5. No differences in FSF were found among the L1, L2, and L3 levels (women, $P=.07$; men, $P=.86$ ). All other FSF level comparisons were significant $(P<.001)$. Higher FSF $(\mathrm{MF}+\mathrm{ES}$, percentage $)$ for both sexes was found at L5 (women: $31.9 \pm 9.3$; men: $25.7 \pm$ 8.0; $P<.001$ ) and L4 (women: $21.2 \pm 9.3$; men: $15.3 \pm 5.3 ; P<$ $.001)$ compared with the supradjacent level. FSF (MF + ES) was higher in women at L1 $(P<.05), \mathrm{L} 3(P<.05), \mathrm{L} 4(P<.001)$, and L5 $(P<.05)($ On-line Table 1$)$.

\section{Muscles}

Total FSF (L1-L5) was higher in the MF than in ES (both sexes, $P<$ $.001)$. For MF and ES separately, FSF (L1-L5) was higher in women $(P<.001)$. According to muscle and level, FSF was higher in the MF than in the ES at L1, L2, L3, and L4 (both sexes, $P<.001$ each) and higher in the ES at L5 in women $(P<.05)($ On-line Table 1 and Fig 1$)$.

\section{Associations}

Associations between variables are presented in Table 2.

A moderate association between FSF (L1-L5) and age was shown (women: $r=0.39, P<.05$; men: $r=0.50, P<.001$ ). FSF at L3 best correlated with age for both sexes, strongly in men (women: $r=0.40$, $P<.05$; men: $r=0.55, P<.001$ ). No association was shown between age and muscle volume or BMI for both sexes. Of the 2 body fat measures, $\mathrm{BIA}_{\text {foot }}$ correlated best with age (women: $r=0.46, P<.01$; men: $r=0.52, P<.001$ ) (Table 2, Figs 1 and 2, and On-line Table 2). 
Strong associations were shown between total FSF (L1-L5) and FSF at L4 (women: $r=0.95, P<.001$; men: $r=0.92, P<$ .001) (Table 2).

No significant correlation occurred between BMI and FSF. A strong correlation occurred between $\mathrm{BMI}$ and $\mathrm{BIA}_{\text {foot }}$ or $\mathrm{BIA}_{\text {hand }}$ (Table 2).

No association was seen between FSF or BMI and consumption-related parameters (weight change, smoking, alcohol/drug use, exercise) or hand/leg dominance (data not shown).

\section{DISCUSSION}

We quantified lumbar paravertebral muscle volume and fat content by using 2-point Dixon whole-body MR imaging of 80 healthy adult volunteers (20-62 years of age) and showed that the lumbar paravertebral muscle fat increased with age, independent of volume. Women, low lumbar levels, and multifidus muscles were most affected; these findings align with degenerative features of the spinal column that are highly prevalent in asymptomatic individuals. $^{30}$

Lumbar paravertebral muscle degeneration occurs in $\mathrm{LBP}^{16-20,24}$ and in response to induced lesions, ${ }^{22}$ yet its prognostic value is unclear. Little is known about normative degeneration, and comparisons with existing literature are limited. Using similar quantification methods with axial 2-point Dixon MR imaging at 1.5T, Fischer et $\mathrm{al}^{5}$ described mean FSF within a region of bilateral multifidus muscles of $21 \%$ (range, 3\%-65\%). Despite their reporting symptomatic cases (potentially higher MFI percentage), our results (for MF / MF + ES) of 23\%/ $18 \%$ in female and $18 \% / 15 \%$ in male lumbar paravertebral muscles appear aligned and may reflect consistent methods. Meakin et $\mathrm{al}^{28}$ interpolated crosssectional areas from axial T1WI in women only, reporting mean $\mathrm{MF}+\mathrm{ES}$ volume caudal to L3-L4 of $303 \mathrm{~cm}^{3}$ (for $n=11$ with no LBP; $281 \mathrm{~cm}^{3}$ in all 42 women). In agreement, our MF + ES volume for women at L4-L5 was 248 $\mathrm{cm}^{3}$. We provide normative FSF and volumes for all lumbar levels in both sexes across 4 decades.

Our fat content age effect agrees with that in other studies reporting MFI in subjects with and without ${ }^{29}$ back pain. ${ }^{17,24,25}$ In disagreement, Fortin et $\mathrm{al}^{18}$ found no correlation with age and FSF cross-sectional areas at L3-L4 or L5-S1 derived from T2WI in men 35-69 years of age. This likely reflects methodologic differences and may relate to their lack of cases representing the 20- to 30-year age group, further highlighting the need for consistency in quantifying paravertebral muscle quality.

FIG 2. Age-group-averaged fat signal fraction (percentage) and muscle volume for both sexes. Multifidus and erector spinae FSFs and muscle volumes are given separately and combined (MF + ES); FSF is shown as a volume-weighted average. FSF and volumes are represented by the sum of both sides (left + right). Significant differences of the means between age groups are indicated by an asterisk $(P<.05)$ and triple asterisks $(P<.001)$. FSF was higher in women than in men at each age group, lumbar level, and muscle (MF + ES, $P<.001$; MF, $P<.01$; ES, $P<.01$ ). Volume was lower in women than in men as indicated by a dagger $(P<.01)$ and double daggers $(P<.001)$.

Table 2: Correlation matrix-men upper right, women lower left

\begin{tabular}{|c|c|c|c|c|c|c|c|c|c|c|c|}
\hline \multirow[b]{2}{*}{ Women } & \multicolumn{11}{|c|}{ Men } \\
\hline & FSF (LI-L5) & FSF (LI) & FSF (L2) & FSF (L3) & FSF (L4) & FSF (L5) & Volume (L1-L5) & Age & BMI & BIA foot $_{\text {for }}$ & $\mathrm{BIA}_{\text {hand }}$ \\
\hline FSF (L1-L5) & & $0.81^{\mathrm{a}}$ & $0.91^{\mathrm{a}}$ & $0.90^{\mathrm{a}}$ & $0.92^{\mathrm{a}}$ & $0.90^{\mathrm{a}}$ & -0.20 & $0.50^{\mathrm{b}}$ & 0.13 & $0.52^{b}$ & $0.43^{b}$ \\
\hline FSF (LI) & $0.86^{a}$ & & $0.86^{\mathrm{a}}$ & $0.71^{\mathrm{a}}$ & $0.61^{\mathrm{a}}$ & $0.62^{\mathrm{a}}$ & -0.25 & $0.34^{c}$ & 0.17 & $0.43^{b}$ & $0.47^{\mathrm{a}}$ \\
\hline FSF (L2) & $0.87^{\mathrm{a}}$ & $0.92^{\mathrm{a}}$ & & $0.90^{\mathrm{a}}$ & $0.80^{\mathrm{a}}$ & $0.68^{a}$ & -0.25 & $0.49^{b}$ & 0.12 & $0.45^{b}$ & $0.40^{c}$ \\
\hline FSF (L3) & $0.93^{\mathrm{a}}$ & $0.82^{\mathrm{a}}$ & $0.87^{\mathrm{a}}$ & & $0.83^{\mathrm{a}}$ & $0.73^{\mathrm{a}}$ & -0.12 & $0.55^{\mathrm{a}}$ & 0.22 & $0.48^{\mathrm{b}}$ & $0.46^{b}$ \\
\hline FSF (L4) & $0.95^{\mathrm{a}}$ & $0.75^{\mathrm{a}}$ & $0.79^{a}$ & $0.90^{\mathrm{a}}$ & & $0.86^{\mathrm{a}}$ & -0.18 & $0.51^{b}$ & 0.08 & $0.47^{b}$ & 0.30 \\
\hline FSF (L5) & $0.90^{\mathrm{a}}$ & $0.69^{\mathrm{a}}$ & $0.65^{\mathrm{a}}$ & $0.76^{\mathrm{a}}$ & $0.83^{\mathrm{a}}$ & & -0.13 & $0.46^{\mathrm{b}}$ & 0.10 & $0.49^{b}$ & $0.39^{c}$ \\
\hline Volume (L1-L5) & -0.03 & -0.23 & -0.20 & -0.02 & 0.00 & 0.07 & & -0.13 & $0.32^{c}$ & 0.06 & 0.30 \\
\hline Age & $0.39^{c}$ & $0.36^{c}$ & $0.36^{c}$ & $0.40^{c}$ & $0.31^{\mathrm{c}}$ & $0.37^{c}$ & 0.08 & & 0.18 & $0.52^{\mathrm{b}}$ & $0.34^{c}$ \\
\hline BMI & -0.08 & -0.11 & -0.17 & -0.07 & -0.07 & 0.02 & 0.29 & 0.03 & & $0.70^{\mathrm{a}}$ & $0.81^{\mathrm{a}}$ \\
\hline BIA $_{\text {foot }}$ & $0.39^{c}$ & $0.35^{c}$ & $0.31^{c}$ & $0.41^{\mathrm{b}}$ & $0.37^{c}$ & $0.36^{c}$ & 0.20 & $0.46^{\mathrm{b}}$ & $0.78^{a}$ & & $0.76^{\mathrm{a}}$ \\
\hline $\mathrm{BIA}_{\text {hand }}$ & 0.20 & 0.18 & 0.14 & 0.19 & 0.16 & 0.18 & 0.21 & 0.00 & $0.76^{a}$ & $0.75^{\mathrm{a}}$ & \\
\hline
\end{tabular}

a $P<.001$.

${ }^{\mathrm{b}} \mathrm{P}<.01$.

${ }^{c} p<.05$. 
We found an age-related increase of MF and ES MFI for both sexes, suggesting progressive worsening in muscle quality, even in healthy individuals. Male participants in each older age group had significantly more MFI in both MF and ES muscles than the youngest men; the third decade of life is an effective baseline for paravertebral muscle degeneration in healthy men. On the contrary, increased MFI in our female participants only occurred in the fifth and sixth decades. These findings may indicate earlier onset of MFI in men and a sex-dependent decline in muscle quality.

We showed an increasing craniocaudal trend for FSF between L1 and L5. Levels L4-L5 had higher MFI compared with the supradjacent level; the upper lumbar spine showed a trend in women (women, $P=.07$; men, $P=.84$ ). This finding agrees with the longitudinal male population study of Fortin et al, ${ }^{17}$ in which L5-S1 had higher MFI than L3-L4. D'Hooge et $\mathrm{al}^{34}$ showed more MFI bilaterally in subjects with LBP compared with healthy controls at both L4 endplates, yet equivalence at the L3 superior endplate. While D'Hooge et $\mathrm{al}^{34}$ did not report interlevel comparisons, agreement exists with respect to a caudal trend for increasing MFI. Our difference between sexes in the upper lumbar spine is interesting. We speculate that muscle quality relates to the intrinsic shape and function of the thoracolumbosacral spine, which may differ between sexes. High paravertebral muscle volume occurs in people with greater lordotic angulation. ${ }^{28}$ While there is conjecture about sex differences in lumbar curvature, ${ }^{35}$ determining spinal shape in relation to MFI could offer clarification.

Plausible explanations behind normative muscle atrophy and MFI exist and include a combination of disuse and denervation secondary to the degenerative cascade and concomitant altered tensile properties of lumbar myofascial and neural tissues. Disuse-related muscle decline purportedly relates to deconditioning, local tensile unload, and altered muscle recruitment. ${ }^{16,19,22}$ Paravertebral muscle denervation occurs in asymptomatic individuals, ${ }^{36}$ and the multifidus muscle is susceptible to the effects of neural stretching after disc height loss and subsequent listhesis. ${ }^{37}$ However, the extent of paraspinal muscle atrophy is not explained by matching denervation; this finding indicates the potential for reversal through activity. ${ }^{38}$ We describe no association of FSF with BMI or exercise, perhaps not supporting either theory. Instead, a local disuse mechanism dependent on paravertebral muscle morphology and proximity to the vertebra as shown in the cervical spine ${ }^{39}$ might better explain the etiology.

Conflicting with several studies reporting laterality in healthy individuals, ${ }^{40}$ those with LBP, ${ }^{19,20,27,28}$ and the general population, ${ }^{17}$ we agree with another study ${ }^{18}$ in showing no differences between sides or hand/leg dominance in our healthy volunteers. Valentin et $\mathrm{al}^{29}$ described asymmetry in MF and ES MFI in their healthy subjects, yet no asymmetry for ES volume. The discrepancy among studies may be due to methodologic differences relating to the types of measurement techniques (quantitative versus qualitative, MR imaging versus CT/sonography, volume versus cross-sectional area), defined paravertebral ROIs, and study samples.

Our valuable methodologic finding promotes more time-effi- cient data collection by using imaging at L4 to generalize for total lumbar paravertebral muscle fat content.

MFI was higher in women than in men at each age group in our series, despite control for BMI in subject selection, resulting in a lower female mean $(P=.05)$. Age-related change to skeletal muscle quality differs for sex-dependence. ${ }^{41}$ Generally, men lose more muscle with aging, yet women have greater functional consequences. ${ }^{41}$ Therefore, the influence of general body fat on healthy paravertebral MFI cannot be ignored. ${ }^{29,34}$ While our study showed no correlation between BMI and FSF, our bioimpedance was strongly associated. Despite the questionable validity of bioimpedance in measuring body fat, ${ }^{42}$ further investigation appears warranted in determining the suitability of BMI or bioimpedance in identifying modifiable risks.

While our study has several strengths, it is limited by being cross-sectional, though it is feasible in assessing a wide age range. Identifying a baseline age group from which to reference the natural history of change represents a valuable contribution to the literature to which longitudinal studies can be directed. We only included participants 20-62 years of age; this age range may not be generalizable to other age groups. Our sample included 10 cases per sex and decade, offering an improvement to the findings in the literature, but was potentially inadequately powered for reference as normative data. Whole-body MRI may not be generalizable to higher resolution clinical scans. Additionally, 2-point Dixon sequences are prone to underestimating FSF; however, we limited the influence by reduction of the flip angle. ${ }^{5}$

Our healthy volunteers evidenced declining muscle quality as a normal process of aging from the twenties into mature adulthood. Investigating whether serial decline continues into healthy older adulthood would be valuable. Furthermore, that poorer muscle quality as determined by increased MFI affects muscle function when noncontractile tissue replaces muscle fibers is implied. Whether this speculation is true should be investigated with applied research examining function.

\section{CONCLUSIONS}

Lumbar multifidus and erector spinae fat content increased with age in healthy adults 20-62 years of age, was higher in women than men, and was more prevalent in the low lumbar levels and in the multifidus compared with erector spinae muscles. These muscle-based degenerative features are part of healthy aging and, relating to LBP, should be interpreted within the individual context. Measurements at L4 are surrogates for the whole lumbar spine. Further studies examining adolescents and adults older than 60 years and in applied research examining function may be helpful in directing interventions aimed at reducing muscle degeneration in the lumbar spine.

\section{ACKNOWLEDGMENTS}

We thank our physicist Roger Luechinger, $\mathrm{PhD}$, for his technical support; Dan Linh Nguygen, MD, for her instruction concerning the analysis software; our radiographers Nicole Aebi, Simone Suess, and Suzanne Potter for performing the MR imaging examinations; Áine Ni Mhuiris, for her assistance in data entry; and Andrew Smith and Marie Wasielewski for their contribution to figure development. 
Disclosures: James M. Elliott—UNRELATED: Consultancy: Relevant financial activities outside the body of work include a $35 \%$ ownership/investment interest in a medical consulting start-up, Pain ID; Grants/Grants Pending: National Institutes of Health, ${ }^{*}$ Comments: 1, R01 HD079076-01A1; project title: Neuromuscular Mechanisms Underlying Poor Recovery from Whiplash Injuries; project duration: September 2014 to May 2019; role: Principal Investigator; Magda Marcon—RELATED: Grant: University Zürich Research Program. * Erika J. Ulbrich—RELATED: Grant: Research Time for Clinical Research at the Medical Faculty of University Zurich (RT-13-014).* *Money paid to the institution.

\section{REFERENCES}

1. Akagi R, Takai Y, Kato E, et al. Development of an equation to predict muscle volume of elbow flexors for men and women with a wide range of age. Eur J Appl Physiol 2010;108:689-94 CrossRef Medline

2. Samagh SP, Kramer EJ, Melkus G, et al. MRI quantification of fatty infiltration and muscle atrophy in a mouse model of rotator cuff tears. J Orthop Res 2013;31:421-26 CrossRef Medline

3. Elliott JM, Flynn TW, Al-Najjar A, et al. The pearls and pitfalls of magnetic resonance imaging for the spine. J Orthop Sports Phys Ther 2011;41:848-60 CrossRef Medline

4. Elliott JM, O'Leary S, Sterling M, et al. Magnetic resonance imaging findings of fatty infiltrate in the cervical flexors in chronic whiplash. Spine 2010;35:948-54 CrossRef Medline

5. Fischer MA, Nanz D, Shimakawa A, et al. Quantification of muscle fat in patients with low back pain: comparison of multi-echo MR imaging with single-voxel MR spectroscopy. Radiology 2013;266: 555-63 CrossRef Medline

6. Reeder SB, Hu HH, Sirlin CB. Proton density fat-fraction: a standardized MR-based biomarker of tissue fat concentration. J Magn Reson Imaging 2012;36:1011-14 CrossRef Medline

7. Elliott J, Pedler A, Kenardy J, et al. The temporal development of fatty infiltrates in the neck muscles following whiplash injury: an association with pain and posttraumatic stress. PLoS One 2011;6: e21194 CrossRef Medline

8. Fischer MA, Pfirrmann CW, Espinosa N, et al. Dixon-based MRI for assessment of muscle-fat content in phantoms, healthy volunteers and patients with achillodynia: comparison to visual assessment of calf muscle quality. Eur Radiol 2014;24:1366-75 CrossRef Medline

9. Smith AC, Parrish TB, Abbott R, et al. Muscle-fat MRI: 1.5 Tesla and 3.0 Tesla versus histology. Muscle Nerve 2014;50:170-76 CrossRef Medline

10. Dixon WT. Simple proton spectroscopic imaging. Radiology 1984; 153:189-94 CrossRef Medline

11. Ma J. Dixon techniques for water and fat imaging. J Magn Reson Imaging 2008;28:543-58 CrossRef Medline

12. Elliott JM, Walton DM, Rademaker A, et al. Quantification of cervical spine muscle fat: a comparison between T1-weighted and multiecho gradient echo imaging using a variable projection algorithm (VARPRO). BMC Med Imag 2013;13:30 CrossRef Medline

13. Paalanne N, Niinimaki J, Karppinen J, et al. Assessment of association between low back pain and paraspinal muscle atrophy using opposed-phase magnetic resonance imaging: a population-based study among young adults. Spine 2011;36:1961-68 CrossRef Medline

14. Elliott JM, Courtney DM, Rademaker A, et al. The rapid and progressive degeneration of the cervical multifidus in whiplash: a MRI study of fatty infiltration. Spine (Phila Pa 1976) 2015;40:E694-700 CrossRef Medline

15. Gaeta M, Scribano E, Mileto A, et al. Muscle fat fraction in neuromuscular disorders: dual-echo dual-flip-angle spoiled gradient-recalled MR imaging technique for quantification-a feasibility study. Radiology 2011;259:487-94 CrossRef Medline

16. Danneels LA, Vanderstraeten GG, Cambier DC, et al. CT imaging of trunk muscles in chronic low back pain patients and healthy control subjects. Eur Spine J 2000;9:266-72 CrossRef Medline

17. Fortin M, Videman T, Gibbons LE, et al. Paraspinal muscle morphology and composition: a 15-yr longitudinal magnetic resonance imaging study. Med Sci Sports Exerc 2014;46:893-901 CrossRef Medline

18. Fortin M, Yuan Y, Battié MC. Factors associated with paraspinal muscle asymmetry in size and composition in a general population sample of men. Phys Ther 2013;93:1540-50 CrossRef Medline

19. Hides J, Gilmore C, Stanton W, et al. Multifidus size and symmetry among chronic LBP and healthy asymptomatic subjects. Man Ther 2008;13:43-49 CrossRef Medline

20. Ploumis A, Michailidis N, Christodoulou P, et al. Ipsilateral atrophy of paraspinal and psoas muscle in unilateral back pain patients with monosegmental degenerative disc disease. Br J Radiol 2011;84: 709-13 CrossRef Medline

21. Teichtahl AJ, Urquhart DM, Wang Y, et al. Fat infiltration of paraspinal muscles is associated with low back pain, disability, and structural abnormalities in community-based adults. Spine J 2015; 15:1593-601 CrossRef Medline

22. Hodges $\mathrm{P}$, Holm AK, Hansson T, et al. Rapid atrophy of the lumbar multifidus follows experimental disc or nerve root injury. Spine 2006;31:2926-33 CrossRef Medline

23. Farshad M, Gerber C, Farshad-Amacker NA, et al. Asymmetry of the multifidus muscle in lumbar radicular nerve compression. Skeletal Radiol 2014;43:49-53 CrossRef Medline

24. Kjaer P, Bendix T, Sorensen JS, et al. Are MRI-defined fat infiltrations in the multifidus muscles associated with low back pain? $B M C$ Med 2007;5:2 CrossRef Medline

25. Mengiardi B, Schmid MR, Boos N, et al. Fat content of lumbar paraspinal muscles in patients with chronic low back pain and in asymptomatic volunteers: quantification with MR spectroscopy. Radiology 2006;240:786-92 CrossRef Medline

26. Parkkola R, Rytökoski U, Kormano M. Magnetic resonance imaging of the discs and trunk muscles in patients with chronic low back pain and healthy control subjects. Spine 1993;18:830-36 CrossRef Medline

27. Barker KL, Shamley DR, Jackson D. Changes in the cross-sectional area of multifidus and psoas in patients with unilateral back pain: the relationship to pain and disability. Spine 2004;29:E515-19 CrossRef Medline

28. Meakin JR, Fulford J, Seymour R, et al. The relationship between sagittal curvature and extensor muscle volume in the lumbar spine. J Anat 2013;222:608-14 CrossRef Medline

29. Valentin S, Licka T, Elliott J. Age and side-related morphometric MRI evaluation of trunk muscles in people without back pain. Man Ther 2015;20:90-95 CrossRef Medline

30. Brinjikji W, Luetmer PH, Comstock B, et al. Systematic literature review of imaging features of spinal degeneration in asymptomatic populations. AJNR Am J Neuroradiol 2015;36:811-16 CrossRef Medline

31. Obesity: preventing and managing the global epidemic: report of a WHO consultation. World Health Organ Tech Rep Ser 2000;894:i-xii, 1-253 Medline

32. Hoffman M, Schrader J, Applegate T, et al. Unilateral postural control of the functionally dominant and nondominant extremities of healthy subjects. J Athl Train 1998;33:319-22 Medline

33. Cassidy FH, Yokoo T, Aganovic L, et al. Fatty liver disease: MR imaging techniques for the detection and quantification of liver steatosis. Radiographics 2009;29:231-60 CrossRef Medline

34. D'Hooge R, Cagnie B, Crombez G, et al. Increased intramuscular fatty infiltration without differences in lumbar muscle cross-sectional area during remission of unilateral recurrent low back pain. Man Ther 2012;17:584-88 CrossRef Medline

35. Been E, Kalichman L. Lumbar lordosis. Spine J 2014;14:87-97 CrossRef Medline

36. Tong HC, Haig AJ, Yamakawa KS, et al. Paraspinal electromyography: age-correlated normative values in asymptomatic subjects. Spine 2005; 30:E499-502 CrossRef Medline

37. Haig AJ, London Z, Sandella DE. Symmetry of paraspinal muscle denervation in clinical lumbar spinal stenosis: support for a hy- 
pothesis of posterior primary ramus stretching? Muscle Nerve 2013; 48:198-203 CrossRef Medline

38. Yarjanian JA, Fetzer A, Yamakawa KS, et al. Correlation of paraspinal atrophy and denervation in back pain and spinal stenosis relative to asymptomatic controls. PM $R$ 2013;5:39-44 CrossRef Medline

39. Abbott R, Pedler A, Sterling M, et al. The geography of fatty infiltrates within the cervical multifidus and semispinalis cervicis in individuals with chronic whiplash-associated disorders. J Orthop Sports Phys Ther 2015;45:281-88 CrossRef Medline
40. Niemelainen R, Briand MM, Battié MC. Substantial asymmetry in paraspinal muscle cross-sectional area in healthy adults questions its value as a marker of low back pain and pathology. Spine 2011;36: 2152-57 CrossRef Medline

41. Doherty TJ. Invited review: aging and sarcopenia. J Appl Physiol 2003;95:1717-27 CrossRef Medline

42. Sillanpää E, Cheng S, Häkkinen K, et al. Body composition in 18- to 88-year-old adults-comparison of multifrequency bioimpedance and dual-energy X-ray absorptiometry. Obesity 2014;22:101-09 CrossRef Medline 